\title{
Effective control of dengue vectors with curtains and water container covers treated with insecticide in Mexico and Venezuela: cluster randomised trials
}

Axel Kroeger, Audrey Lenhart, Manuel Ochoa, Elci Villegas, Michael Levy, Neal Alexander, P J McCall

\begin{abstract}
Objectives To measure the impact on the dengue vector population (Aedes aegypti) and disease transmission of window curtains and water container covers treated with insecticide. Design Cluster randomised controlled trial based on entomological surveys and, for Trujillo only, serological survey. In addition, each site had a non-randomised external control. Setting 18 urban sectors in Veracruz (Mexico) and 18 in Trujillo (Venezuela).

Participants 4743 inhabitants (1095 houses) in Veracruz and 5306 inhabitants (1122 houses) in Trujillo.

Intervention Sectors were paired according to entomological indices, and one sector in each pair was randomly allocated to receive treatment. In Veracruz, the intervention comprised curtains treated with lambdacyhalothrin and water treatment with pyriproxyfen chips (an insect growth regulator). In Trujillo, the intervention comprised curtains treated with longlasting deltamethrin (PermaNet) plus water jar covers of the same material. Follow-up surveys were conducted at intervals, with the final survey after 12 months in Veracruz and nine months in Trujillo.
\end{abstract}

Main outcome measures Reduction in entomological indices, specifically the Breteau and house indices.

Results In both study sites, indices at the end of the trial were significantly lower than those at baseline, though with no significant differences between control and intervention arms. The mean Breteau index dropped from 60\% (intervention clusters) and 113\% (control) to 7\% (intervention) and 12\% (control) in Veracruz and from $38 \%$ to $11 \%$ (intervention) and from $34 \%$ to $17 \%$ (control) in Trujillo. The pupae per person and container indices showed similar patterns. In contrast, in nearby communities not in the trial the entomological indices followed the rainfall pattern. The intervention reduced mosquito populations in neighbouring control clusters (spill-over effect); and houses closer to treated houses were less likely to have infestations than those further away. This created a community effect whereby mosquito numbers were reduced throughout the study site. The observed effects were probably associated with the use of materials treated with insecticide at both sites because in Veracruz, people did not accept and use the pyriproxyfen chips.

Conclusion Window curtains and domestic water container covers treated with insecticide can reduce densities of dengue vectors to low levels and potentially affect dengue transmission.

\section{Introduction}

Dengue is the most common and fastest spreading human arboviral disease worldwide. ${ }^{1}$ In the absence of a vaccine, control of the vector mosquito, Aedes aegypti, is the only effective preventive measure. Reduction of mosquito breeding in household water vessels through larvicides, predatory crustaceans, ${ }^{23}$ or elimination of discarded containers, and control of adult mosquitoes by spraying with insecticide, require a continuous effort by the community ${ }^{4}$ and can be difficult to sustain ${ }^{5}$ and expensive. An appropriate community intervention is clearly needed.

Bed nets treated with insecticide can prevent transmission of nocturnally transmitted vector-borne diseases including malaria, ${ }^{6}$ Chagas' disease, ${ }^{7}$ leishmaniasis, ${ }^{8}$ and lymphatic filariasis. ${ }^{9}$ Such materials have not been used to control the vectors of dengue. We tested the efficacy of window curtains treated with insecticide combined with water container interventions in reducing dengue entomological and serological indices.

\section{Methods}

\section{Study areas}

In Mexico (October 2002 to November 2003) we conducted our study in Agua Dulce (20 $21^{\prime} \mathrm{N} 97^{\circ} 17^{\prime} \mathrm{W}$; altitude $\left.110 \mathrm{~m}\right), 10 \mathrm{~km}$ from the city of Papantla, Veracruz. There is one rainy season (June-October), the mean annual rainfall is $1160 \mathrm{~mm}$, and the mean temperature $21^{\circ} \mathrm{C}$. All households were eligible, and 4743 people in 1095 households (99.99\%) participated in the study. No activities to control mosquitoes had been carried out in the four months before the study.

In Venezuela (January to November 2003) we carried out the study in Trujillo $\left(9^{\circ} 22^{\prime} \mathrm{N} 70^{\circ} 26^{\prime} \mathrm{W}\right.$, altitude $800 \mathrm{~m}$, population 53 000). There are two rainy seasons (March/April and November), the mean annual rainfall is $750 \mathrm{~mm}$, and temperatures range from $16-37^{\circ} \mathrm{C}$. We selected one large suburb of the city (Santa Rosa), in which limited interventions to control mosquitoes (larviciding and aerial spraying) had been carried out in previous months. All households were eligible, and 1122 households with 5306 inhabitants were included (99.99\%). Figures 1 and 2 show the flow of households through the study.

\section{Study design}

We conducted a cluster randomised trial at each site. We randomised clusters, rather than houses, because we expected movement of mosquitoes to spread the effects of the interventions between houses. We used a sample size of nine pairs of clusters as a conservative estimate because seven pairs had been sufficient in a previous trial in Trujillo. ${ }^{8}$ No interim 


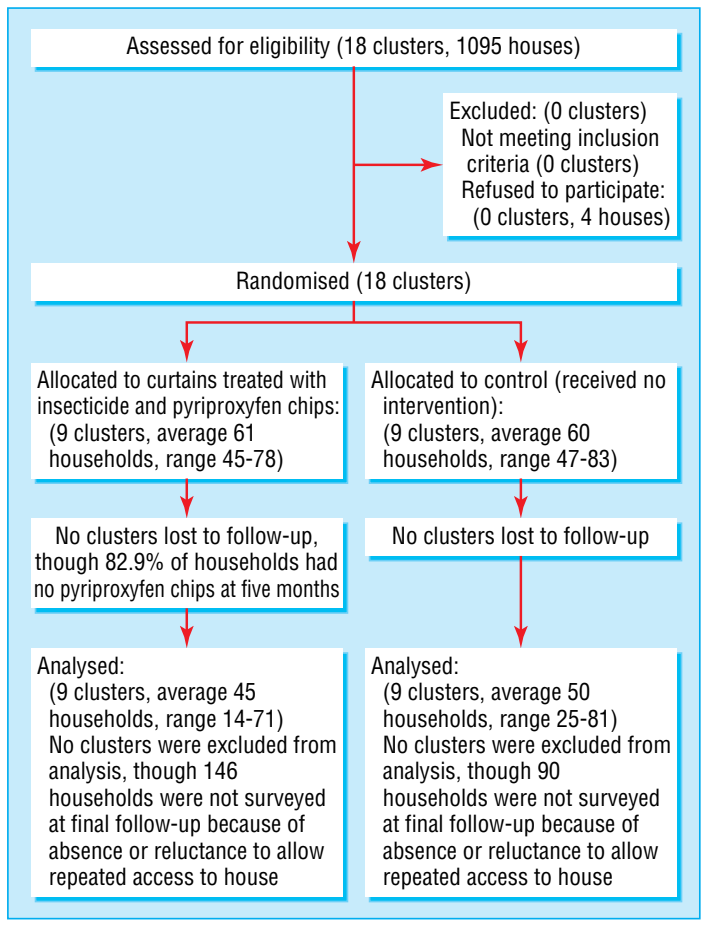

Fig 1 Flow of households in Veracruz through study

analysis or stopping rule was planned or executed. Each study site was divided into 18 sectors of similar size (means of 61 and 62 houses per sector in Veracruz and Trujillo, respectively). Sectors were separated by streets of about $6 \mathrm{~m}$ wide.

\section{Baseline surveys}

After informed consent from authorities and communities, we carried out baseline surveys in all study sectors to measure various indices (see box). Our primary end points were the Breteau

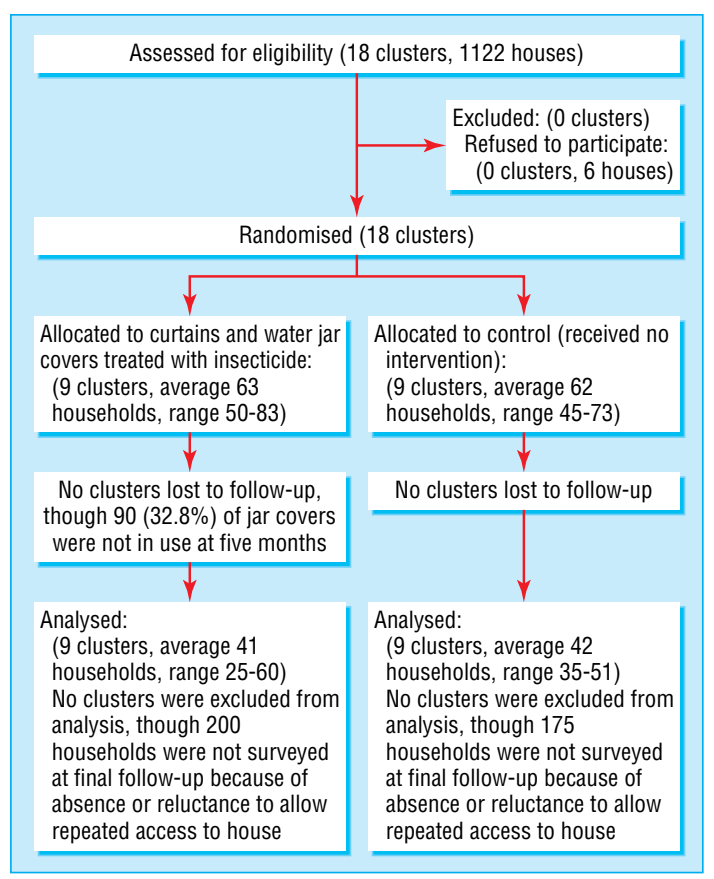

Fig 2 Flow of households in Trujillo through study index and the house index; the secondary end points were the pupae per person index, the container index, and IgM serology.

\section{Pairing of sectors}

We paired clusters (sectors) taking into account baseline values of Breteau index, house index, and housing conditions (house size, condition and number of walls, and house density). One sector from each pair was randomly allocated to the intervention or control arm by a member of the research team tossing a coin in the presence of colleagues. This maintained the investigators' "ignorance of the upcoming assignment" ${ }^{2}$ of each sector, so the allocation was, in effect, concealed, though not blinded.

\section{Interventions}

The interventions were applied at house level. In Veracruz, households received polyester net curtains treated by hand with insecticide $(2.5 \%$ lambacyhalothrin at target concentration 15 $\mathrm{mg} / \mathrm{m}^{2}$ netting) hung loosely at the windows (mean 2.8 curtains per household). Initially, chips of the larval growth inhibitor pyriproxyfen (slow release formulation, active ingredient $27 \mathrm{ppb}$, Sumitomo Chemical, Japan ${ }^{13}$ ) in a cloth infusion bag were suspended in all water containers of 10 litres or more, which had been shown in the baseline study to be the most productive breeding places. Control sectors received no interventions, and therefore the study was not blind. Acceptance rates of pyriproxyfen were low: only 29\% (881/3022) of containers still had bags after two weeks, and only $17 \%(372 / 2172)$ at five months. Moreover, we found around two thirds of these remaining bags in wells, which do not contribute greatly to the vector population. We concluded that this intervention did not contribute significantly to the trial outcome and have not discussed it further.

In Trujillo, intervention houses received PermaNet curtains (netting treated with long lasting insecticide; deltamethrin 50 $\mathrm{mg} / \mathrm{m}^{2}$, Vestergaard-Frandsen, Denmark) and circular water jar covers (PermaNet netting with an elastic rim). Control sectors received no interventions, and therefore the study was not blind. Curtains were used as in Veracruz and covers provided for all household water drums (typically 150-200 l), where most vector breeding occurred. In both study sites the curtains were impregnated again after five to six months with lambacyhalothrin

\section{Surveys carried out in all study sectors}

Standard larval surveys ${ }^{10}$ :

Breteau index (number of containers with immature stages per 100 houses)

House index (number of houses containing immature stages per 100 houses)

Container index (number of containers with immature stages per 100 containers with water)

Pupal surveys to calculate the number of pupae per person index (number of pupae collected/human population in a sector) Ovitrap surveys ${ }^{11}$ to calculate the proportion of indoor, outdoor, and total ovitraps positive for Aedes eggs after seven days of trap exposure (ovitrap index: \% of houses with one or two ovitraps with Aedes eggs)

Interview surveys and key informant interviews to determine household characteristics and previous vector control intervention

Georeferencing each house with a handheld global positioning system receiver (Magellan, California, USA)

Serological surveys to determine IgM concentrations as indicators for recent dengue infection ${ }^{1}$ (Trujillo only) 
(15 mg/m $\mathrm{m}^{2}$ ) because of the expected decrease of insecticide activity with direct exposure to sunshine. The numbers of participating households fell by $22 \%$ in Veracruz and 33\% in Trujillo because of absence of heads of household and because people tired of letting researchers enter their premises.

\section{Entomological monitoring}

After two to four weeks and at four months after the intervention began we carried out the same measurements as in the baseline study. Final data were collected after 12 months in Veracruz and nine months in Trujillo. For external control data we used entomological data collected as part of routine surveillance by Ministry of Health vector control programmes in neighbouring areas (Veracruz Jurisdicciòn Sanitaria No III; Trujillo municipality, including Trujillo city).

Rainfall data were obtained for the city of Trujillo (Dirección de Hidrología y Meteorología, Sistema Nacional de Información Hidrológica y Meteorológica) and the state of Veracruz (Instituto Nacional de Estadística, Geografia e Informática).

\section{Serological survey}

A house-to-house serosurvey was carried out in Trujillo when the intervention began (March 2003; 698 houses) and eight months later (November 2003; 640 houses). Houses were selected randomly from both control and intervention clusters. After receiving informed consent, a blood sample was taken by venous puncture from one individual aged $>15$ years (usually the housewife). Samples were analysed for anti-dengue IgM by enzyme linked immunosorbent assay (ELISA) with a standard kit (UM-ELISA test, Centro de Imunoensayo, Havana, Cuba) including all reagents and standards. ${ }^{14} \mathrm{~A}$ value of 0.225 fluorescence units (FU) measured automatically (TecnoSuma Internacional PR521 ELISA reader, Havana, Cuba) as optical density was considered to indicate recent dengue infection.

\section{Attitudes of participants}

We gauged attitudes towards the interventions through informal interviews at the beginning and end of the study and with a satisfaction survey conducted with heads of household in intervention clusters at the final follow-up only.

\section{Statistical analysis}

For each of the four entomological indices, we used paired $t$ tests to compare intervention and control areas and baseline and final follow-up data, each sector contributing one data point according to intention to treat. We also adjusted comparisons between arms for baseline values and achieved similar results. A two sided $\mathrm{P}$ value of 0.05 was considered significant. We assessed variation between sectors in the Breteau index by the coefficient of variation of baseline values $(k)$, using the method for rates described by Hayes and Bennett. ${ }^{15}$ The value of $k$ was 0.71 in Veracruz and 0.10 in Trujillo. The value for house index, treated as a proportion, was 0.22 in Veracruz. In Trujillo, the method yielded a negative value for $k^{2}$, as can happen when estimating variance components, which we interpret as a low degree of clustering. Clustering of the house index was assessed at various spatial scales by comparing the difference in Ripley's $K$ statistic between positive and negative houses. ${ }^{16}$ Confidence intervals were determined through simulation. ${ }^{16}{ }^{17}$ Spill-over effect between clusters was assessed by calculating the odds ratio of nearby positive houses becoming negative at two weeks, relative to more distant positive houses. The spill-over analysis did not include the intervention status of each house's sector and was carried out at four distances at each site; the Bonferroni correc- tion was applied and a two sided $\mathrm{P}$ value of 0.0125 was considered significant.

\section{Results}

\section{Window curtains treated with insecticide}

At baseline, the mean Breteau and house indices in Veracruz were $86 \%$ and $41 \%$ respectively, mean pupae per person index was 2.7 and the ovitrap index was $31 \%$. After the intervention began the mean Breteau and house indices immediately fell in the intervention households (from $60 \%$ to $46 \%$ and from $36 \%$ to $19 \%$, respectively, at two weeks after the intervention) and in the control households (Breteau index from 113\% to 87\% and house index from $45 \%$ to $30 \%$ ) (fig 3). In the next months the fall continued to low levels in both intervention and control sectors. At 12 months, the mean Breteau and house indices were lower in the intervention arm but not significantly so $(\mathrm{P}=0.27$ and 0.16 , respectively (table 1). Both indices, however, showed a clear decline after baseline in both intervention and control arms. The Breteau index fell from 60\% to $7 \%(\mathrm{P}<0.001)$ in the intervention group and from $113 \%$ to $12 \%$ in the control group $(\mathrm{P}=0.02)$, with the house index falling from $36 \%$ to $6 \%(\mathrm{P}<0.001)$ and from $45 \%$ to $10 \%(\mathrm{P}=0.001)$, respectively. Similar reductions in intervention group were also seen in the pupae per person index (from 3.4 at baseline to 0.36 after 12 months; table 2), the container index (from $7 \%$ to $1 \%$ ), and the ovitrap index (from $28 \%$ to $11 \%$ ), with comparable but less dramatic declines occurring in control groups (pupae per person index from 2.0 to 0.35 ; container index from $14 \%$ to $2 \%$; ovitrap index from $33 \%$ to $16 \%)$.

\section{Window curtains and water container covers treated with insecticide}

At baseline in Trujillo, large household water drums (150-200 l) comprised $57.8 \%$ of all positive containers, and nearly a quarter $(24 \%, 245 / 1008)$ of these drums was positive for vector larvae or pupae, or both. Shortly after the intervention began there were significant reductions in intervention sectors in the Breteau index (from 38\% to 12\%), the house index (from 19\% to 7\%), and the pupae per person index (from 3.0 to 0.3 (table 2) (fig 2). After nine months, as in Veracruz, there was no significant difference between control and intervention arms $(\mathrm{P}=0.18$ for both Breteau and house indices). Reductions from baseline, however, were significant or borderline (table 1). Interestingly, the ovitrap index showed a different pattern, increasing from $25 \%$ to $39 \%$ after four months and then slowly falling to the original level after 10 months (25\%). Moreover, the container index barely changed, from $5 \%$ to $4 \%$ after four months and 4\% after 10 months. Presumably, without access to preferred breeding sites, vectors were diverted to other sites.

Prevalence of IgM measured at baseline was 16\% (64/398) and $21 \%(62 / 300)$ in intervention and control clusters, respectively. After eight months, this had dropped to $8 \%$ $(27 / 330)$ in the intervention clusters but had not changed significantly in the control groups $(18 \%, 56 / 310)$. The paired test for the mean difference at eight months gave a $\mathrm{P}$ value of 0.06 .

\section{Evidence for a community-wide effect}

These findings suggest a spill-over effect occurred, whereby the intervention affected neighbouring control clusters, reducing their vector populations. This is consistent with the following findings.

Firstly, in external control sites remote from the interventions, seasonal changes in the vector population were markedly different to those within the study sectors. In these sites 
Table 1 Breteau and house indexes in nine pairs of sectors in Veracruz and Trujillo. Numbers are percentages (positive/total)

\begin{tabular}{|c|c|c|c|c|c|c|c|c|}
\hline \multirow{3}{*}{$\begin{array}{l}\text { Pair } \\
\text { number }\end{array}$} & \multicolumn{4}{|c|}{ Breteau index (positive containers/hundred houses) } & \multicolumn{4}{|c|}{ House index ( $\%$ of houses with positive containers) } \\
\hline & \multicolumn{2}{|c|}{ Baseline } & \multicolumn{2}{|c|}{ Final follow-up* } & \multicolumn{2}{|c|}{ Baseline } & \multicolumn{2}{|c|}{ Final follow-up† } \\
\hline & Intervention & Control & Intervention & Control & Intervention & Control & Intervention & Control \\
\hline \multicolumn{9}{|l|}{ Veracruz } \\
\hline 1 & $59(41 / 69)$ & $67(50 / 75)$ & $10(7 / 71)$ & $25(18 / 72)$ & $26(18 / 69)$ & $36(27 / 75)$ & $10(7 / 71)$ & $22(16 / 72)$ \\
\hline 2 & $81(63 / 78)$ & $78(36 / 46)$ & $27(17 / 63)$ & $10(3 / 30)$ & $42(33 / 78)$ & $33(15 / 46)$ & $18(11 / 63)$ & $10(3 / 30)$ \\
\hline 3 & $69(34 / 49)$ & $233(98 / 42)$ & $2(1 / 41)$ & $20(8 / 40)$ & $51(25 / 49)$ & $83(35 / 42)$ & $2(1 / 41)$ & $13(5 / 40)$ \\
\hline 4 & $59(33 / 56)$ & $84(43 / 51)$ & $0(0 / 57)$ & $2(1 / 42)$ & $38(21 / 56)$ & $55(28 / 51)$ & $0(0 / 57)$ & $2(1 / 42)$ \\
\hline 5 & $94(71 / 75)$ & $352(264 / 75)$ & $20(11 / 54)$ & $8(4 / 50)$ & $53(40 / 75)$ & $64(48 / 75)$ & $19(10 / 54)$ & $8(4 / 50)$ \\
\hline 6 & $38(17 / 45)$ & $89(42 / 47)$ & $4(1 / 27)$ & $11(5 / 45)$ & $36(16 / 45)$ & $49(23 / 47)$ & $4(1 / 27)$ & $11(5 / 45)$ \\
\hline 7 & $39(25 / 64)$ & $53(25 / 47)$ & $0(0 / 51)$ & $12(3 / 25)$ & $23(15 / 64)$ & $43(20 / 47)$ & $0(0 / 51)$ & $12(3 / 25)$ \\
\hline 8 & $61(38 / 62)$ & $28(23 / 83)$ & $0(0 / 29)$ & $10(8 / 81)$ & $29(18 / 62)$ & $23(19 / 83)$ & $0(0 / 29)$ & $5(4 / 81)$ \\
\hline 9 & $35(19 / 55)$ & $30(23 / 76)$ & $0(0 / 14)$ & $8(5 / 67)$ & $29(16 / 55)$ & $20(15 / 76)$ & $0(0 / 14)$ & $8(5 / 67)$ \\
\hline Mean & 60 & 113 & 7 & 12 & 36 & 45 & 6 & 10 \\
\hline \multicolumn{9}{|l|}{ Trujillo } \\
\hline 1 & $2(1 / 63)$ & $0(0 / 67)$ & $0(0 / 36)$ & $4(2 / 51)$ & $2(1 / 63)$ & $0(0 / 67)$ & $0(0 / 36)$ & $4(2 / 51)$ \\
\hline 2 & $87(66 / 76)$ & $112(74 / 66)$ & $23(11 / 47)$ & $43(16 / 37)$ & $37(28 / 76)$ & $38(25 / 66)$ & $19(9 / 47)$ & $35(13 / 37)$ \\
\hline 3 & $55(46 / 83)$ & $53(39 / 73)$ & $13(8 / 60)$ & $40(18 / 45)$ & $39(32 / 83)$ & $36(26 / 73)$ & $8(5 / 60)$ & $33(15 / 45)$ \\
\hline 4 & $22(14 / 65)$ & $6(4 / 65)$ & $14(6 / 44)$ & $5(2 / 41)$ & $11(7 / 65)$ & $6(4 / 65)$ & $14(6 / 44)$ & $5(2 / 41)$ \\
\hline 5 & $28(17 / 60)$ & $20(13 / 66)$ & $12(5 / 41)$ & $6(3 / 48)$ & $22(13 / 60)$ & $20(13 / 66)$ & $12(5 / 41)$ & $4(2 / 48)$ \\
\hline 6 & $49(33 / 67)$ & $47(34 / 73)$ & $30(14 / 46)$ & $26(9 / 35)$ & $25(17 / 67)$ & $30(22 / 73)$ & $24(11 / 46)$ & $23(8 / 35)$ \\
\hline 7 & $66(33 / 50)$ & $47(22 / 47)$ & $8(3 / 37)$ & $17(7 / 41)$ & $18(9 / 50)$ & $26(12 / 47)$ & $5(2 / 37)$ & $15(6 / 41)$ \\
\hline 8 & $10(5 / 51)$ & $6(3 / 52)$ & $0(0 / 25)$ & $9(4 / 44)$ & $6(3 / 51)$ & $4(2 / 52)$ & $0(0 / 25)$ & $9(4 / 44)$ \\
\hline 9 & $25(13 / 53)$ & $16(7 / 45)$ & $0(0 / 32)$ & $3(1 / 37)$ & $13(7 / 53)$ & $16(7 / 45)$ & $0(0 / 32)$ & $3(1 / 37)$ \\
\hline Mean & 38 & 34 & 11 & 17 & 19 & 19 & 9 & 15 \\
\hline
\end{tabular}

${ }^{*}$ Overall change at follow-up from baseline was $-53(95 \% \mathrm{Cl}-64$ to -41$), \mathrm{P}<0.001$, in the intervention group and -101 ( -184 to -18$), P=0.02$, in the control group in Veracruz, with a difference between intervention and control at final follow-up of $-5(-14$ to 4$), P=0.27$. For Trujillo the figures were $-27(-44$ to -10$), P=0.007$, in the intervention group and -17 ( -34 to 0.2$)$, $P=0.052$, in the control group, with a difference of $-5 .(-15$ to 3$), P=0.18$.

tOverall change at follow-up from baseline was -31 ( -38 to -24$), P<0.001$, in the intervention group and $-35(-51$ to -19$)$, $P<0.001$, in the control group in Veracruz, with a difference between intervention and control at final follow-up of $-4(-11$ to 2$), P=0.16$. For Trujillo the figures were $-10(-18$ to -2$), P=0.018$, in the intervention group and -5 ( -10 to 0.7$)$, $P=0.080$, in the control group, with a difference of -5 (-14 to 3$), P=0.18$.

(Veracruz: 5616 water containers in 945 houses examined; Trujillo: 21542 water containers from 4557 houses), the seasonal patterns of larval indices and the monthly rainfall data (fig 3) correspond well, particularly in Veracruz. The dramatic population increase in vector populations during the rainy season in late 2003 did not occur at all in the study sectors, where vector numbers did not recover in response to the rains.

Secondly, spatial analysis indicated that houses located closer to treated houses were less likely to have infestations than those further away. In Veracruz at two weeks after the intervention,
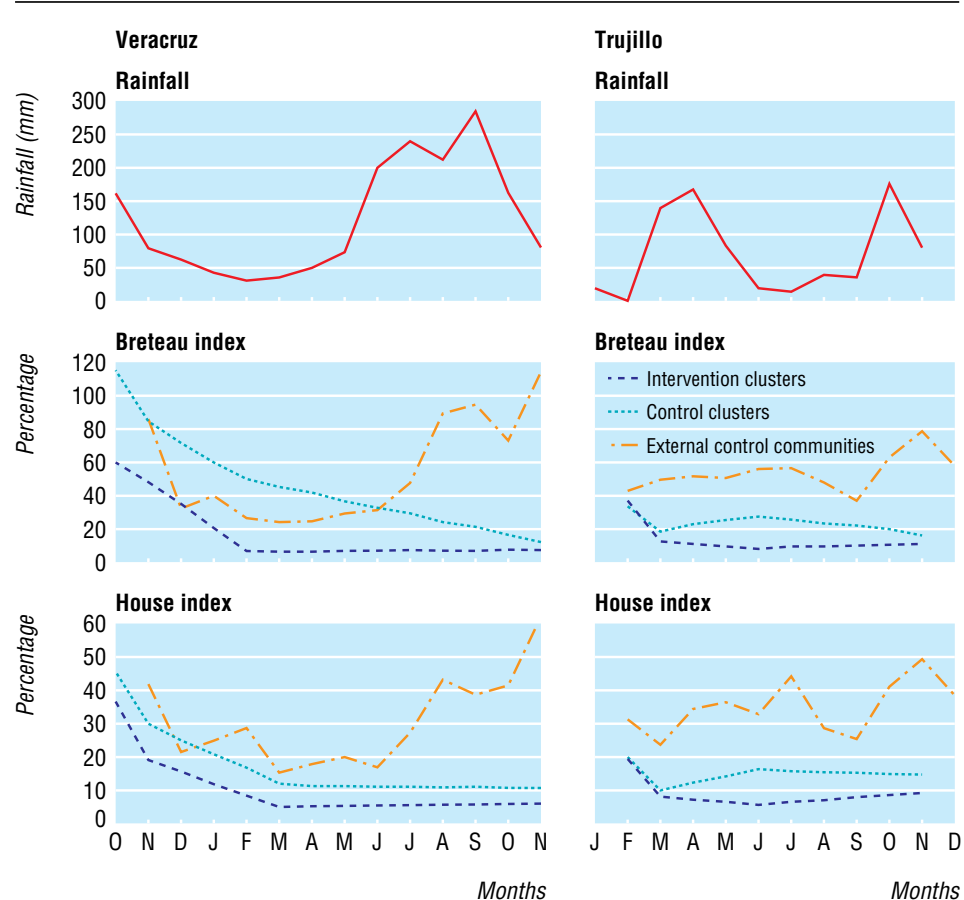

Fig 3 Breteau and house indices in intervention and control clusters and in external control communities at baseline and end of studies in Veracruz (Mexico) and Trujillo (Venezuela), with monthly local rainfall data 
control houses that were located within $10 \mathrm{~m}$ of an intervention house were twice as likely (odds ratio $2.02, \mathrm{P}=0.01$ ) to be negative for Aedes larvae and pupae compared with positive control houses further away. In Trujillo, where houses were more dispersed than in Veracruz, initially positive control houses within $50 \mathrm{~m}$ of the nearest intervention house were 3.5 times as likely to be free of vectors than more distant initially positive control houses one month after the intervention, though this difference was not significant $(\mathrm{P}=0.06)$.

\section{Acceptance of interventions}

Acceptance of curtains at both sites was high: two weeks after intervention $95 \%(524 / 553)$ and $87 \%(492 / 568)$ of houses in Veracruz and Trujillo, respectively, had at least one treated curtain; the proportions were $88 \%(403 / 456)$ in Veracruz and $96.0 \%(386 / 402)$ in Trujillo at five months. At formal and informal interviews household members remarked positively on the variety of dead insects found daily below the treated curtains.

In Trujillo, acceptance of water jar covers was also high: of the 283 jar covers originally distributed, 68\% (193/283) were still in use after five months. Although these covers were generally well accepted, they were not always used correctly. Moreover, they were not durable and tore easily with constant use. In both sites there were no reported adverse events attributed to the interventions.

\section{Discussion}

Use of curtains and jar covers made with material treated with insecticide can reduce the number of dengue vectors and potentially reduce disease transmission. Previous studies of such materials have shown reductions in morbidity and mortality associated with other vector-borne diseases mortality (malaria, ${ }^{6}$

Table 2 Pupae per person index (No of pupae/No of people) in nine pairs of sectors in Veracruz and Trujillo

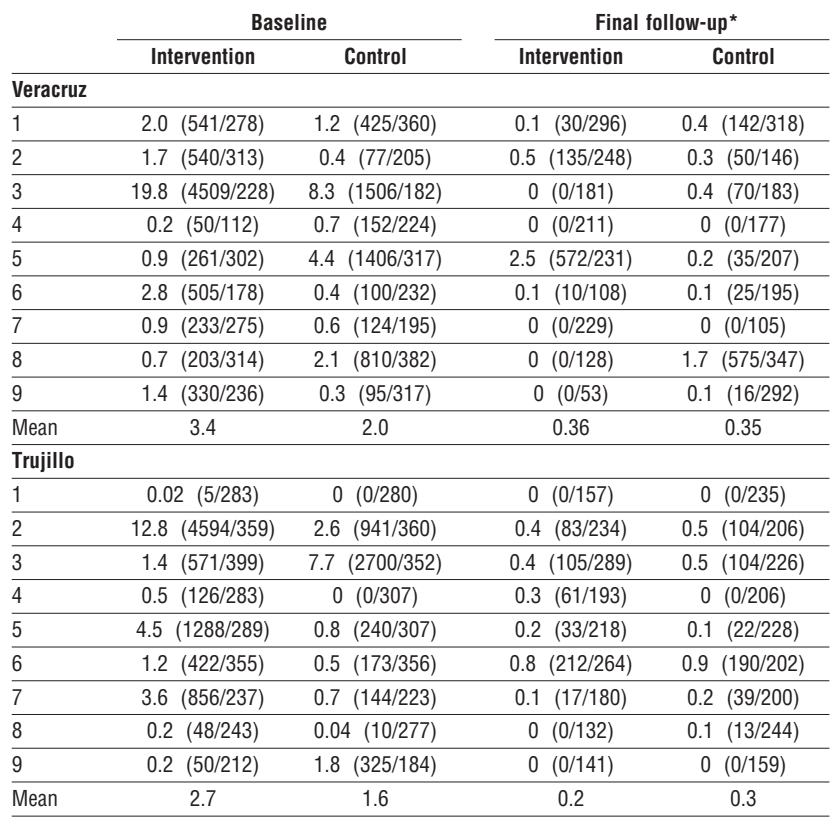

*Overall change at follow-up from baseline was $-3.0(95 \% \mathrm{Cl}-7.9$ to 1.9$), \mathrm{P}=0.19$, in the intervention group and -1.7 ( -3.7 to 0.4$), P=0.09$, in the control group in Veracruz, with a difference between intervention and control at final follow-up of 0.004 (-0.78 to 0.79 ), $\mathrm{P}=0.99$. For Trujillo the figures were $-2.5(-5.6$ to 0.6$), \mathrm{P}=0.1$, in the intervention group and -1.3 (-3.1 to 0.52$), P=0.14$, in the control group, with a difference between intervention and control at final follow-up of $-0.02(-0.13$ to 0.09$), P=0.71$.

\section{What is already known on this topic}

Vector control aimed at reducing the density of the dengue vector, Aedes aegypti, to low levels is the only presently available measure for preventing dengue transmission

Larviciding, insecticide spraying or elimination of domestic water containers through community involvement are labour intensive and often difficult to sustain

\section{What this study adds}

Use of window curtains treated with insecticide alone or in combination with treated jar covers can substantially reduce the dengue vector population and potentially reduce disease transmission

leishmaniasis ${ }^{8}$ ) and reduction of risk of transmission through entomological indices (leishmaniasis, ${ }^{8}$ Chagas' disease ${ }^{7}$ ).

\section{Limitations and strengths}

We assumed that the mosquitoes were more sedentary in the domestic environment and would not disperse far, whereas they may have achieved their flight range. ${ }^{18}{ }^{19}$ Thus the proximity of intervention and control clusters led to a spill-over effect, shown by the spatial analysis, that masked the magnitude of the effect of the intervention on the mosquito population and on disease transmission. This would explain why differences between control and intervention arms were not significant. However, the study also showed a marked and prolonged reduction in the dengue vector population that continued during the wet season. By contrast, untreated dengue vector populations in the external control communities had increased in the months after the intervention. Thus the treated materials in the intervention households had both a household and, as shown by the spill-over, a community-wide effect on dengue vectors. The extent of the latter indicates that the materials may have an additional advantage that could greatly enhance the efficacy of the intervention. A previous study on malaria and bed nets treated with insecticide, in which distances between many control and intervention households were well within the flight range of the vector, also showed a community-wide reduction of both vectors and disease. ${ }^{20} 21$

In addition to the comparisons between arms, we carried out a before and after assessment to analyse the reduction occurring within the intervention and control arms. This showed reductions in the Breteau and house indices and also in the pupae per person index, which is now known to be most highly associated with the density of adult vectors. ${ }^{10}$ As these comparisons are not between randomised arms, they are potentially subject to bias, in particular due to temporal trends in vector density. The lack of such trends in the external control areas, however, suggests that the interventions did, in fact, cause the observed reductions. The Trujillo serological study further suggests that the intervention significantly affected dengue transmission, as shown by the reduction in dengue IgM prevalence in intervention clusters compared with control clusters.

On the basis of these data, larger trials of materials treated with insecticide alone and in combination with other interventions are now starting in Asia and Latin America, where we hope to confirm their efficacy at a household and community level for control of dengue vectors and disease prevention. 


\section{Research}

Carmen Elena Castillo organised the serosurvey and Milagros Oviedo assisted with entomological monitoring in Trujillo; Oscar Aldana, IMSS-OPORTUNIDADES, Mexico, collected the external control data in Veracruz; and Manuel Zorrilla organised the fieldwork in Veracruz. Field support was provided by staff from IMSS-OPORTUNIDADES (Mexico) and Universidad de los Andes (Venezuela). Support by various authorities-J Cabral, C Escandon (IMSS-OPORTUNIDADES) and J Mendez Galvan (Secretaría de Salud) in Mexico, and J Scorza and E Rojas (Universidad de los Andes) in Venezuela-was crucial.

Contributors: AK, AEL, PJMcC, MO, EV, and CEC participated in the design and execution of the study. All authors contributed to interpretation, analysis, and preparation of the manuscript. AK is guarantor

Funding: British Council, Sir Halley Stewart Trust, Simpson Education and Conservation Trust. ML received a Howard Hughes fellowship. PermaNet materials were donated by Vestergaard Frandsen, lambdacyhalothrin by Syngenta, and pyriproxyfen by the Sumitomo Corporation.

Competing interests: None declared.

Ethical approval: Liverpool School of Tropical Medicine, local ethical committees at IMSS-OPORTUNIDADES, Mexico, and the Universidad de los Andes, Venezuela.

1 PAHO. Dengue and dengue hemorrhagic fever in the Americas: guidelines for prevention and control. Washington: Pan American Health Organization, 1994. (Scientific Publication No 548.)

2 Kay B, Vu SN. New strategy against Aedes aegypti in Vietnam. Lancet 2005;365:613-7.

3 Vu SN, Nguyen TY, Tran VP, Truong UN, Le QM, Le VL, et al. Elimination of dengue by community programs using Mesocyclops (Copepoda) against Aedes aegypti in central Vietnam. Am Trop Med Hyg 2005;72:67-73.

4 Parks W, Lloyd L. Planning social mobilization and communication for dengue fever preven tion and control. Geneva: WHO, 2004. (WHO/CDS/WMC/2004.2.)

5 Nathan BM, Knudsen AB. Aedes aegypti infestation characteristics in several Caribbean countries and implications for integrated community-based control. J Am Mosq Cont Ass 1991;7:400-4.

6 Nahlen BL, Clark JP, Alnwick D. Insecticide-treated bednets. Am J Trop Med Hyg 2003; 68(4 suppl):1-2.

7 Kroeger A, Villegas E, Ordoñez-Gonzalez J, Pabon E, Scorza JV. Prevention of the transmission of Chagas disease with pyrethroid-impregnated materials. Am J Trop Med Hyg 2003;68:307-11.

8 Kroeger A, Villegas E, Morison L. Insecticide-impregnated curtains to control domestic transmission of cutaneous leishmaniasis in Venezuela: cluster randomised trial. BMJ 2002;325:810-3.

9 Pedersen EM, Mukoko DA. Impact of insecticide-treated materials on filaria transmission by the various species of vector mosquito in Africa. Ann Trop Med Hyg 2002;96(suppl):S91-5.

10 Focks D. A review of entomological sampling methods and indicators for dengue vectors. Geneva: WHO, 2004. (WHO/TDR/IDE/Den.03.1.)

11 Lenhart AE, Walle $\mathrm{H}$, Cedillo $\mathrm{H}$, Kroeger A. Building a better ovitrap for detecting Aedes aegypti oviposition. Acta Trop 2005;5:56-9.
12 Schulz KF, Grimes DA. Allocation concealment in randomized trial: defending against deciphering. Lancet 2002;359:614-8

13 World Health Organization. Review of insect growth regulator pyriproxyfen GR. In Report of the 4th WHOPES working group meeting. Geneva: WHO/CDS/WHOPES, 2001:50-67.

14 Acosta C, Melchor A, Alonso V, Solis RL, Vazquez S. Dengue IgM detection UltramicroELISA test with ready-to-use reagents. Medic C Review 2005;7:21-7.

15 Hayes RJ, Bennett S. Simple sample size calculation for cluster-randomized trials. Int J Epidemiol 1999;28:319-26.

16 Diggle PJ, Chetwynd AG. Second-order analysis of spatial clustering for inhomogeneous populations. Biometrics 1991;47:1155-63

17 Waller LA, Gotway CA. Applied spatial statistics for public health data. Hoboken, NJ:John Wiley, 2004.

18 Reiter P, Amador MA, Anderson RA, Clark GG. Short report: dispersal of Aedes aegypti in an urban area after blood feeding as demonstrated by rubidium-marked eggs. Am J Trop Med Hyg 1995;52:177-9.

19 Muir LE, Kay BH. Aedes aegypti survival and dispersal estimated by mark-releaserecapture in northern Australia. Am J Trop Med Hyg 1998;58:277-82.

20 Gimnig JE, Kolczak MS, Hightower AW, Vulule JM, Schoute E, Kamau L, et al. Effect of permethrin-treated bed nets on the spatial distribution of malaria vectors in Western Kenya. Am J Trop Med Hyg 2003;68(suppl 4):115-20.

21 Hawley WA, Phillips-Howard PA, ter Kuile FO, Terlouw D, Vulule JM, Ombok M, et al. Community-wide effects of permethrin-treated bed nets on child mortality and malaria morbidity in Western Kenya. Am J Trop Med Hyg 2003;68(suppl 4):121-7.

(Accepted 9 March 2006)

bmj.com 2006;332:1247

Special Programme for Research and Training in Tropical Medicine (TDR/WHO), World Health Organization, Geneva, Switzerland

Axel Kroeger scientist

Liverpool School of Tropical Medicine, Liverpool L3 5QA

Audrey Lenhart research assistant

P J McCall senior lecturer in medical entomology

IMSS-OPORTUNIDADES, Col Juarez CP 06600 Mexico City, Mexico

Manuel Ochoa institutional coordinator

Universidad de los Andes, Nucleo Rafael Rangel, Centro de Investigaciones Josè Witremundo Torrealba, Trujillo, Venezuela

Elci Villegas university professor

Program in Population Biology, Evolution and Ecology, Division of Biological and Biomedical Sciences, Emory University, Atlanta, GA, USA

Michael Levy research assistant

London School of Hygiene and Tropical Medicine, London WC1E 7HT

Neal Alexander senior lecturer in medical statistics and epidemiology

Correspondence to: A Kroeger kroegera@who.int 